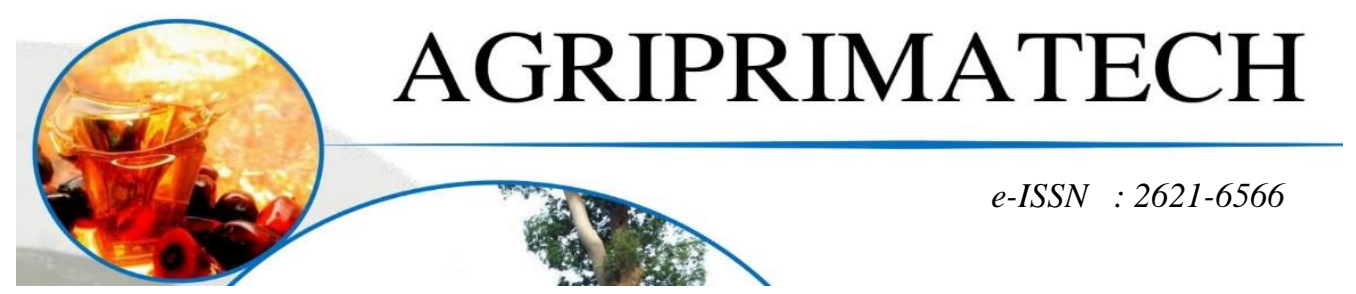

\title{
PENANGANAN PENGANGKUTAN BARANG MELALUI CONTAINER PADA PT. ELANG SRIWIJAYA PERKASA PALEMBANG
}

\author{
${ }^{1}$ DAFID GINTING, ${ }^{2}$ MUHAMMAD SAHID, ${ }^{3}$ DODO FERNANDO SURBAKTI \\ ${ }^{1,2}$ NAUTIKA, Politeknik Adiguna Maritim Medan \\ ${ }^{3}$ KPNK, Politeknik Adiguna Maritim Medan \\ email: dafidginting@amimedan.ac.id.
}

\begin{abstract}
ABSTRAK
Pengangkutan adalah kegiatan pemuatan kedalam alat pengangkut, pemindahan ke tempat tujuan dengan alat pengangkut, dan penurunan/pembongkaran dari alat pengangkut baik mengenai penumpang ataupun barang.Pihak penunjang dalam pengangkutan salah satunya adalah Ekspedisi Muatan Kapal Laut ( EMKL) adalah usaha pengurusan dokumen dan muatan yang akan diangkut melalui kapal atau muatan yang berasal dari kapal yang di angkut dan dibawa ke gudang bongkar atau membawa barang melalui container dari gudang muat ke pelabuhan.PT.Elang Sriwijaya Perkasa Palembang merupakan salah satu perusahaan yang bergerak dalam bidang EMKL (Ekspedisi Muatan Kapal Laut) menyediakan jasa angkutan transportasi kargo, dalam memenuhi jasa pengiriman barang melaluicontainer serta bongkar muat.

Untuk itu perusahaan Ekspedisi Muatan Kapal Laut (EMKL) bertanggung jawab atas keselamatan barang, kelambatan datang nya barang, kerusakan dan kehilangan suatu barang yang diangkut pada saat pengangkutan, kecuali kerusakan kerusakan yang diakibatkan oleh pengirim karena suatu cacat pada barang itu sendiri disebabkan oleh beberapa factor baik cuaca, keadaan maupun pada saat melakukan kegiatan Stuffing atau memuat barang ke containerpada saat di gudang. Dalam makalah ini, metode penulisan yang digunakan yaitu penelitian kepustakaan dan penelitian lapangan pada sumbernya dengan melakukan kegiatan di lapangan selama melakukan praktek di PT. Elang Sriwijaya Perkasa Palembang dan Instansi yang terkait seperti gudang muat barang stuffing, gudang bongkar barang stripping, dan lapangan penumpukan / Depo seperti BGR (Bhanda Graha Reksa) Depo MTKI (Masaji Tatanan Kontainer Indonesia).
\end{abstract}

Kata Kunci: : Pengangkutan,Container, Lapangan, Penumpukan, Peti Kemas 


\section{PENDAHULUAN}

Containeratau yang dalam bahasa indonesia sering disebut sebagai peti kemas adalah salah satu kemasan yang dirancang secara khusus dengan ukuran tertentu, dapat dipakai berulang kali, dipergunakan untuk menyimpan dan segaligus mengangkut muatan yang ada didalam nya. Filosopi dibalik peti kemas ini adalah adanya kemasan yang terstandar yang dapat dipindah-pindahkan ke berbagai moda transportasi laut dan darat dengan mudah seperti kapal laut, kereta api,truck, atau angkutan lainnya sehingga transportasi ini lebih efesien,cepat,dan aman. Dari fungsinya yang mempunyai banyak kemudahan transportasi ini, container akhirnya menjadi pilihan utama pengangkutan barang, terutama untuk lintas pulau atau lintas negara.

$$
\text { Menurut Amir, M.S (2018:41) }
$$

Berdasarkan Customs Convention on Containers ,yang dimaksud dengan container adalah alat untuk mengangkut barang yang: a). Seluruh atau sebagian tertutup sehingga berbentuk peti atau kerat dan dimaksud untuk di isi barang yang akan di angkut, b).Berbentuk permanen dan kokoh sehingga dapat di gunakan berulang kali untuk pengangkutan barang. c).Dibuat sedemikian rupa sehingga memungkinkan dalam pengangkutan barang dengan suatu kendaraan tanpa terlebih dahulu di bongkar Kembali. d).Dibuat sedemikian rupa untuk langsung dapat diangkut, khususnya apabila di pindahkan dari satu ke lain kendaraan. e).Dibuat sedemikian rupa sehingga mudah diisi dan dikosongkan.

Banyak nya pihak yang terkait dalam pengangkutan barang untuk kegiatan ekspor maka dilingkup ekspor maupun ekspor tidak mudah. Para pihak ekspedisi muatan kapal laut harus mampu menguasai dibidangnya agar memberikan penanganan yang baik dan aman untuk memperlancar kegiatan pengangkutan barang ekspor maupun impor jika tidak, ini akan menimbulkan suatu kerugian yang sangat banyak. Maka untuk itu para pihak ekspedisi muatan kapal laut (EMKL) mempersiapkan pemahaman dan pengetahuan mengenai jasa ini, supaya penangananpengangkutan ekspedisi ini sebagai sarana untuk mewujudkan sistem pengelolaan barang menjadi efesien,cepat,tepat,dan aman (dengan memanfaatkan beberapa sistem informasi dan teknologi saat ini)

Rencana pengangkutan barang yang mencakup semua peti kemas yang akan dimuat keatas truck dan akan dilakukan pemuatan barang kedalam container harus sudah direncanakan sebelum kapal tiba di pelabuhan. Dalam hal ini banyak terjadi hambatan-hambatan yang harus ditangani oleh pihak ekspsdisi mulai dari pemilihan containeryang sesuai spesifikasi eksportir, disini seringkali terjadi keteledoran pihak operasional dalam menjalankan tugas dan tanggungjawab nya dalam pemilihan container yang baik, seringkali terjadi kesalahan dalam pemilihan container dan salah muat container kosongkeatas mobil truck ini menyebabkan sering adanya penolakan dan pemulangan container setelah berada digudang muat barang, serta pengangkutan barang melalui container juga harus ditangani dengan baik agar tidak terjadi insiden dan keterlambatan barang yang akan merugikan perusahaan ekspedisimaka untuk itu pihak operasional harus mempunyai koordinasi yang baik dengan eksportir dan pihak/lembaga yang terkait.

Adapun tindakan yang dilakukan pada saat penanganan pengangkutan barang melalui container adalah pihak operasional wajib melakukan pemeriksaan terhadap container yang berkondisi baik (goodcondition) sesuai spesifikasi dari pihak eksportir, setelah itu membayar biaya untuk lift-on di lapangan penumpukan petikemas/depo container untuk melakukan pemuatan container kosong keatas mobil truck, menjalankan pelaksanaan kegiatan stuffing/ muat barang di gudang eksportir sesuai tanggal yang sudah di perjanjikan pihak eksportir dengan pihak ekspedisi, serta 
mengadakan pengawasan pada saat muat barang di gudang eksportir, pihak operasional harus melakukan pengawasan dan membuat dokumentasi pada saat muat barang kedalam container berlangsung. Ini sangatlah penting untuk menjaga keamanan dan kondisi barang, supaya dapat memberikan penanganan yang baik agar tidak terjadi kerusakan barang dari gudang muat sampai ke pelabuhan terminal petikemas boom baru palembang.

\section{METODE PENELITIAN}

Sebelum menyusun penelitian tentunya membutuhkan bahan-bahan dan fakta yang dapat mendukung penulis sehingga dimengerti oleh pembaca. Dalam penyusunan penelitian ini menggunakan metode sebagai berikut: 1.Metode Lapangan(Field Research) a.Observasi

Dalam metode ini penulis secara langsung mengamati PT. Elang Sriwijaya Perkasa Palembang, yang bergerak di dibidang jasa penanganan pengangkutan barang melalui container.

\section{b.Metode wawancara ( Interview )}

Metode ini penulis secara langsung melakukan wawancara dan menanyakan secara langsung kepada sumbernya atau yang berkaitan seperti karyawan atau orang yang memahami tentang penanganan pengangkutan barang melalui container dengan cara mewawancarainya atau menanyakan langsung secara tatap muka antara pewawancara dengan karyawan PT. Elang Sriwijaya Perkasa Palembang.

Metode ini dilakukan melalui perpustakaan untuk mendapatkan data dan informasi yang bersumber dari buku pendukung yang ada hubungannya dengan masalah yang di teliti untuk menunjang penelitian penulis dalam menyelesaikan penulisan ini.
HASIL DAN PEMBAHASAN

\section{A.Sejarah Singkat Perusahaan}

\section{Sejarah PT. Elang Sriwijaya Perkasa Palembang}

PT. Elang Sriwijaya Perkasa, yang beralokasi di Jl. R.W Mongonsidi Perumahan Casa Feliz B-2 kalidoni Palembang. PT. Elang Sriwijaya Perkasa adalah sebuah perusahaan logistic, yang meyediakan berbagai layanan dalam pelayaran, pengiriman barang, pergudangan, dan menyediakan transportasi darat, pengangkutan barang melalui container, bongkar muat cargo keseluruh Indonesia. Dengan adanya jasa Ekspedisi Muatan Kapal Laut ini tentunya sangat membantu pendistribusian barang eskpor maupun impor.

\section{B.PenangananPengangkutan Barang Melalui Container Pada PT. Elang Sriwijaya Perkasa.}

PT. Elang Sriwijaya Perkasa adalah perusahaan ekspedisi muatan kapal laut yang berperan penting dalam pengangkutan barang melaluicontainer juga menyediakan berbagai layanan dalam pelayaran, pengiriman barang, pergudangan, danmenyediakan transportasi darat, bongkar muat kargo.

Dalam seminggu perusahaan ini dapat mengangkut lebih 20 container menuju ke Terminal Tetikemas Palembang.

a).Penanganan container di lapangan penumpukan Petikemas/ Depo.

Sebelum penanganan container ke depo pihak eksportir terlebih dahulu memberikan list container untuk di lakukan pemeriksaan terhadap container yang sesuai spesifikasi pesanan eksportir, bagian operasional mencari container yang bagus dan layak untuk dipakai sesuai jenis muatan yang di akan di muat. setelah itu pihak operasional mengirimkan container yang sudah di periksa dan layak untuk di pakai ke perusahaan pelayaran. Untuk penerbitan DO ( Delivery Order) dan akan dilakukan proses stuffing / pemuatan barang di gudang eksportir dengan waktu yang sudah disepakati oleh pihak ekspsdisi dan eksportir. Pihak eksportir 
mengirimkan dokumen Nota Pelayanan Ekspor (NPE), Pemberitahuan Ekspor Barang(PEB),dan Shipping Intructionkepada pihak ekspedisi untuk pembayaran lift off di pelabuhan yang akan di bayarkan oleh bagian staff dokumen PT. Elang Sriwijaya Perkasa Palembang melalui website IPCSERVICE . Pihak operasional menuju ke lapangan penumpukan container untuk membayar biaya lift on untuk container kosong yang sudah di pesan ke loket MTKI (Masaji Tantanan Kontainer Indonesia) dengan memberikan dokumen DO ( Delivery Order)

b.Penanganan pengangkutan barang melalui container pada PT. Elang Sriwijaya Perkasa Palembang.

Bagian operasional meminta sopir untuk membawa mobil truck menuju lapangan penumpukan / depo untuk mengambil container kosong di pindahkan melalui alat fork lift ke atas mobil truck, setelah selesai muat container kosong pihak operasional akan memberikan kitir muat yang sudah di berikan bagian gate depo MTKI (Masaji Tantanan Kontainer Indonesia) kepada bagian Tally lapangan penumpukan sebagai tanda bahwa container yang sudah kita pesan sudah keluar dari lapangan penumpukan petikemas. Bagian operasional memerintahkan kepada sopir untuk langsung menuju gudang eksportir untuk kegiatan stuffing / pemuatan barang muatan dan dipasang seal di bagian pintu container, setelah itu di angkut ke pelabuhan terminal petikemas palembang.

\section{C.Jasa Pelayanan PT. Elang Sriwijaya Perkasa \\ PT. Elang Sriwijaya Perkasa menawarkan jasa diantaranya:}

a).Jasa EMKL

Pelayanan jasa EMKL PT. Elang Sriwijaya Perkasa menyediakan berbagai layanan dalam pelayaran, pengiriman barang, pergudangan, distribusi dan menyediakan transportasi darat, bongkar muat kargo keseluruh Indonesia. Dalam pelayanan jasa ini pemesanan jasa dapat memilih berbagai ukuran container di antara nya :

1.Kontainer $20 \mathrm{ft}$ dengan dimensi luar Panjang $6,058 \mathrm{~m}$, lebar $2,48 \mathrm{~m}$ dan tingggi $2,591 \mathrm{~m}$.

2.Kontainer $40 \mathrm{ft}$ dengan dimensi luar Panjang $12,192 \mathrm{~m}$, lebar $2,48 \mathrm{~m}$ dan tinggi 2,591m.

b).Jasa Truck

Perusahaan ini menyediakan jasa truck dalam proses pengiriman barang eskpor melalui container, jumblah truck perusahaan ini adalah 20 unit. Peranan pelayanan truck untuk ekspor dilakukan dengan mengangkut container kosong dari lapangan penumpukan / Depo container menuju gudang eksportir, kemudian diangkut ke pelabuhan. Peranan pelayanan impor juga dilakukan dengan cara membawa container dari pelabuhan menuju gudang Importir untuk proses bongkar barang.

\section{D.Daftar Istilah-Istilah DalamEMKL} (Ekspedisi Muatan Kapal Laut)

\section{Stuffing}

Proses Loading/muat barang muatan kedalam container.

\section{Striping}

Proses bongkar barang atau pengosongan container.

\section{Lo-Lo}

a.Lift On : Menaikkan container ke atas alat pengangkut.

b.Lift Off : Menurunkan container dari alat pengagkut.

4.CFS (Container Freight Station)

Gudang tempat stuffing dan stripping container.

5.Detention

Biaya yang dikenakan karena pemilik barang mengembalikan container melewati batas free time.

6.Surcharge

Biaya yang dikenakan kepada pihak EMKL karena pihak ekspedisi mengembalikan container kosong di lapangan penumpukan melewati batas Free Time.

7.LCL ( Less Container load )

Pengiriman barang dengan wadah satu container yang terdiri dari beberapa pengirim.

8.FCL ( full Container Load ) 
Pengiriman barang dengan wadah satu container di isi penuh oleh satu pengirim.

9.ETA ( Estimation Time Arrival )

Adalah perkiraan waktu kedatangan kapal.

10.ETD ( Estimation Time Departure )

Adalah perkiraan waktu keberangkatan kapal.

11.Truck.

Adalah sebuah transportasi yang di gunakan guna mengangkut container menuju gudang atau pelabuhan.

E.Jenis-Jenis Alat Pemuatan Container Keatas Mobil Truck Pada PT. Elang Sriwijaya Perkasa.

Adapun Jenis alat angkut container saat ini adalah sebagai berikut:

1.Fork Lift.

Alat yang dapat bergerak dan memiliki garpu / fork yang digunakan untuk menaikkan / menurunkan ( Lift on/Lift Off ) container di lapangan penumpukan.

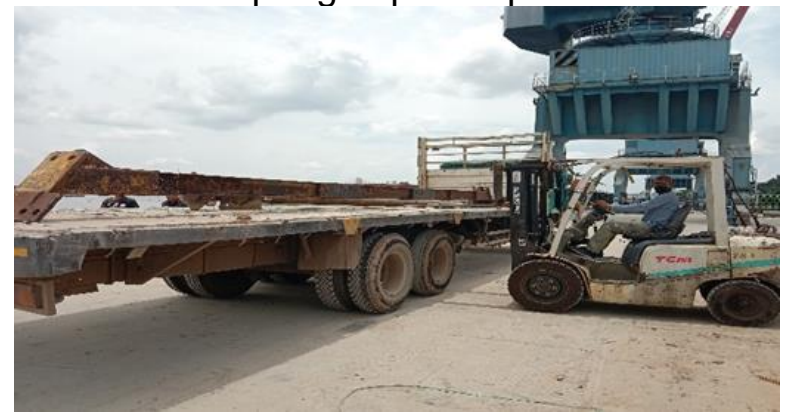

Sumber PT. Elang Sriwijaya Perkasa Palembang

\section{Side Loader}

Berfungsi untuk menurunkan dan menaikkan container di lapangan penumpukan / depo container.

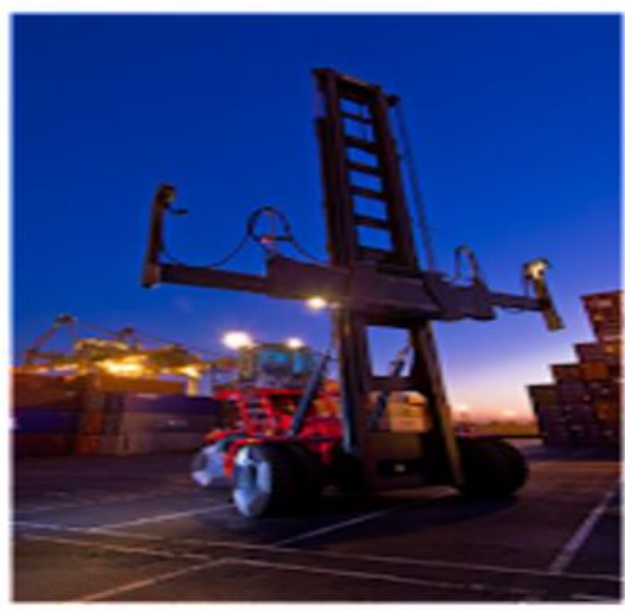

Sumber PT. Elang Sriwijaya Perkasa Palembang

\section{Reach Stacker}

Alat yang dapat bergerak yang memiliki spreader di gunakan untuk menaikkan / menurunkkan ( Lift on / Lift Off ) di lapangan penumpukan maupun pelabuhan.

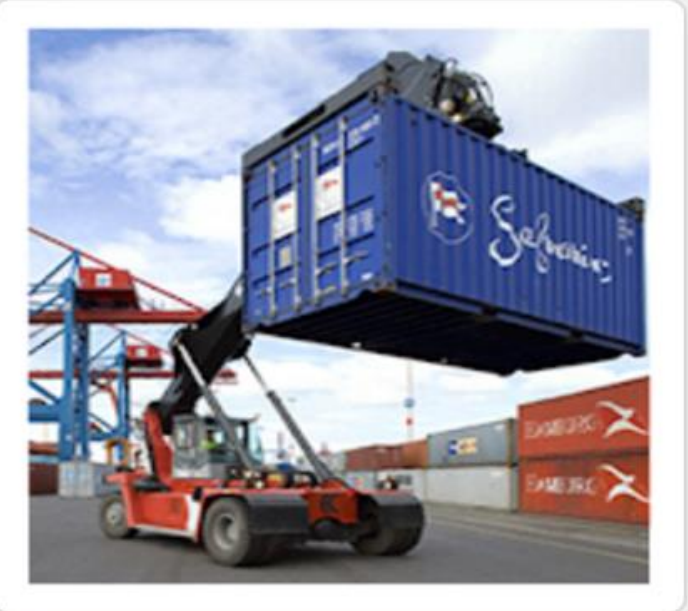

Sumber PT. Elang Sriwijaya Perkasa Palembang

\section{Mobil Truck}

Adalah sebuah transportasi pengangkut peti kemas terdiri dari kendaraan penarik ( Tractor head ) dan kereta tempelan dimana petikemas di tempelkan. 


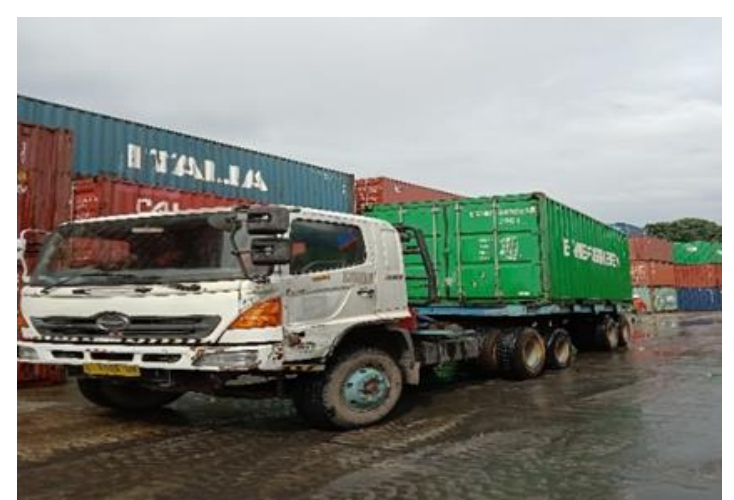

Sumber PT. Elang Sriwijaya Perkasa

Palembang

\section{F.Proses Pengangkutan Barang Ekspor PT. Elang Sriwijaya Perkasa}

Pelaksanaan proses jasa pengangkutan ekspor pada PT. Elang Sriwijaya Perkasa adalah sebagai berikut:

a.Importir melakukan persetujuan transaksi dengan eksportir.

b.Eksportir mengirimkan delivery order dan shipping instruction kepada PT. Elang Sriwijaya Perkasa melalui email atau facsimile dan akan mencatatnya di laporan schedule harian yang berisi eksportir sebagai shipper, importir atau penerima barang sebagai consigne, tujuan pengiriman, perusahaan pelayaran, ukuran container, dan jumblah yang di pesan.

c.Bagian dokumen PT. Elang Sriwijaya Perkasa akan membuat dokumen Pemberitahuan Ekspor Barang (PEB) berdasarkan delivery order dan shipping instruction yang dikirimkan oleh eksportir.

d.Bagian dokumen akan memberikan Salinan/ foto copy dokumen delivery order kepada bagian operasional, lalu bagian operasional akan mencarikan truck di garasi PT. Elang Sriwijaya Perkasa.

e.Bagian operasional menuju ke depo container dengan mencari spesifikasi yang sesuai pesanan eksportir, membayar biaya sewa lalu membuat surat jalan dan memerintahkan operator untuk menaikkan container kosong ke atas truck.
f.Bagian operasional menuju perusahaan pelayaran untuk meminta segel yang nanti akan di pasang di pintu container.

g.Truck akan menuju gudang eksportir untuk melakukan stuffing / pemuatan barang.

h.Setelah melakukan pemuatan barang truck menuju pelabuhan melalui gate terminal petikemas Palembang.

i.Bagian dokumen akan mengirim dokumen DO, PEB, dan NPE ke pihak pelabuhan yang bertugas di terminal petikemas Palembang untuk membayar biaya lift off jika truck sudah sampai di pelabuhan.

j.Bagian operasional akan melakukan dokumentasi terhadap container yang sudah berisi barang eskpor sebelum masuk ke pelabuhan.

\section{G.Proses Pengangkutan Barang Impor PT. Elang Sriwijaya Perkasa}

Pelaksanaan proses jasa transportasi impor pada PT. Elang Sriwijaya Perkasa adalah sebagai berikut:

a.Importir mengirimkan delivery order kepada PT. Elang Sriwijaya Perkasa melalui email atau faxsimile dan mencatatnya ke shadule impor lalu akan meminta surat kuasa untuk pengambilan bill of lading.

b.Bagian dokumen menyerahkan surat kuasa ke bagian operasional untuk menuju perusahaan shipping line.

c.Bagian dokumen membayar biaya lift on di pelabuhan melalui website IPCSERVICE menggunakan dokumen delivery order.

d.Bagian operasional menuju ke garasi truck untuk meminta sopir untuk membawa truck ke pelabuhan Terminal Petikemas sambal membuat surat jalan.

e.Setelah pihak PT. Elang Sriwijaya Perkasa selaku ekspedisi selesai membayar biaya lift on, pihak pelabuhan akan mengecek nomor dan memuat container ke atas truck. 
f.Sebelum menuju gudang importir truck bagian operasional akan melakukan dokumentasi foto terhadap container bagian samping, kiri, pintu container, serta segel container.

g.Setelah selesai melakukan pembongkaran barang ke gudang importir maka sopir akan mengembalikan container ke depo.

\section{H.Dokumen-Dokumen Yang Digunakan Dalam Pengangkutan Barang Melalui Container}

\section{B/L ( Bill Of Lading )}

Adalah dokumen pengangkutan barang yang didalamnya memuat informasi lengkap mengenai nama pengirim, nama kapal, data muatan, pelabuhan muat dan pelabuhan bongkar, dan cara pembayarannya.

\section{SI ( Shipping Instruction )}

Adalah surat yang dibuat shipper (pemilik barang atau perusahaan ekspedisi) yang ditujukan kepada carrier/kapal untuk menerima dan memuat muatan yang tertera dalam surat tersebut.

\section{DO ( Delivery Order )}

Adalah dokumen yang berfungsi sebagai surat tersebut, yang ditujukan kepada bagian yang menyimpan barang (bagian gudang) milik perusahaan atau bagian gudang perusahaan lain yang memiliki konsensus dengan perusahaan yang menerbitkan Delivery Order.

\section{PEB (Pemberitahuan Ekspor Barang)}

Adalah dokumen pabean yang
digunakan untuk pemberitahuan
pelaksanaan ekspor barang

\section{NPE (Nota Pelayanan Ekspor)}

Adalah nota yang diterbitkan oleh pejabat pemeriksaan dokumen, sistem komputer pelayanan, atau pejabat pemeriksaan barang atas PEB yang disampaikan, untuk melindungi pemasukan barang yang akan diekspor kekawasan pabean.

\section{Invoice}

Adalah dokumen yang digunakan sebagai suatu bukti pembelian yang berisi jumblah pembayaran yang harus dibayar oleh pembeli.

\section{Packing List}

Adalah dokumen packing atau pengemasan yang menunjukkan jumblah, jenis, serta berat dari barang ekspor.

\section{Surat jalan}

Adalah sebuah dokumen atau surat yang mencantumkan semua barang yang termasuk dalam pengiriman, nama sopir, plat mobil nomor lambung mobil/Truck. dan tanda pelaksanaan pengangkutan.

\section{I.Biaya Jasa PT. Elang Sriwijaya Perkasa Palembang}

Besarnya biaya yang dikenakan kepada pelanggan PT. Elang Sriwijaya Perkasa Palembang tergantung dari ukuran, jenis container, dan lokasi barang yang akan dikirim atau diangkut. Berikut perincian biaya yang akan di keluarkan:

a.Biaya Container

Biaya dalam penaikkan container kosong keatas truck berbeda-beda tergantung dengan perusahaan penyedia container. berikut adalah biaya di salah satu depo container

\section{b.Biaya Trucking}

Merupakan biaya yang dikenakan pemesanan jasa dalam pengiriman barang dari gudang eksportir ke pelabuhan maupun dari gudang importir. Besar nya biaya truck tergantung dengan jarak tempuh gudang dan pelabuhan.

\section{c.Biaya Penumpukan}

Biaya yang dikenakan dalam penumpukan container di pelabuhan adalah untuk container .

\section{J.Faktor Penghambat Dalam Proses Pengangkutan Barang Melalui Container Pada PT. Elang Sriwijaya Perkasa}

Dalam pelakasanaan jasa perusahaan ekspedisi muatan kapal laut 
tidak selalu berjalan dengan baik, terkadang ada kendala yang mengakibatkan proses tersebut mengalami keterlambatan diantaranya:

1.Keterlambatan pengiriman dokumen oleh pihak eksportir Maupun importir mengakibatkan terhambatnya proses pengiriman barang.

2.Terjadinya kekurangan container, dimana kebutuhan eksportir akan container tidak dapat terpenuhi.

3.Terlalu banyak container yang tidak sesuai dengan spesifikasi oleh pihak eksportir.

4.Sering kali terjadinya kerusakan pada truck pengangkut, sehingga mengakibatkan proses stuffing menjadi terhambat.

5.Kurangnya Kerjasama antara pihak lapangan depo container dengan pihak EMKL, atau kurang nya koordinasi sehingga lambat dalam bekerja.

6.Seringkali terjadi kerusakan alat pemindah container di depo seperti Forklift dan sideloader sehingga memperlambat proses lift-on.

7. Hambatan berupa faktor adanya wabah penyakit covid-19 di tahun 2020 menjadi salah satu kendala atau memperhambat dalam proses pengangkutan barang melalui container.

8.Kurangnya komunikasi antara sopir dengan staf operasioanal lapangan sehingga sopir sering tidak mengikuti aturan pekerjaan.

\section{KESIMPULAN}

Penanganan pengangkutan barang melalui container pada PT. Elang Sriwijaya Perkasa Palembang sudah sesuai dengan standard operation procedure (SOP) perusahaan namun masih ada hambatan yang terjadi dilapangan penumpukan petikemas, gudang muat barang, dan pelabuhan sehingga sering kali terjadi kesalahan dan keterlambatan pada kegiatan barang ekspor maupun impor.

\section{DAFTAR PUSTAKA}

Amir, M.S. Petikemas: Masalah dan aplikasinya.Jakarta: Pustaka Binama Pressindo, 2018

Amir, M.S. Ekspor-Impor : Teori dan penerapannya.Jakarta: penerbit PPM,2005

Captain L.G Taylor Extra Master,M.N: Cargo Handing, The Care, Handling and Carriage of Cargoes, Glasgow Brown, Son \& Ferguson,Ltd,Nautical Publishers 4-10 Darnley Street.

John R. Immer: Cargo Handing, Work Saving International $1638 \quad 19^{\text {th }} \quad$ St.N.W. Washington,D.C.20009

Prof, Dr. Herman Budi Santoso, SE, MM. : Manajemen Impor dan Importasi Indonesi.Yogyakarta,2013

Suharjo, Ana Retnoningsih, Kamus Besar Bahasa Indonesia: Edisi Lux.Semarang: Widya Karya.2017

Kamus Besar Bahasa Indonesia (KBBI), (https://lektur.id/arti-pengangkutan) 